\title{
Bariatric Surgery: An Evolving Field
}

\author{
Bruce Wolfe
}

Published online: 21 July 2009

(C) Société Internationale de Chirurgie 2009

It is appropriate that John G. Hunter, Editor of the World Journal of Surgery, requested a symposium devoted to Bariatric Surgery. The obesity epidemic has indeed become a worldwide problem [1]. For multiple reasons the number of bariatric procedures presently being performed in the United States and internationally has accelerated dramatically in recent years. The American Society for Metabolic and Bariatric Surgery estimates that 220,000 procedures were performed in 2008 in the United States alone [2]. This dramatic increase in the number of bariatric surgical procedures can be attributed to the reasons outlined below.

\section{The obesity epidemic}

All of the contributors to this symposium have made reference to the progressive obesity epidemic. Of greatest concern is that the frequency of the most severe BMI strata is accelerating most rapidly [3].

\section{Identification of the pathophysiology of obesity}

Increasing strength of the evidence establishing an association of obesity with premature mortality and a wide variety of comorbid conditions including type 2 diabetes, obstructive sleep apnea, and multiple malignancies, among many others, has become more definitive relatively

\section{B. Wolfe $(\square)$}

Department of Surgery, Oregon Health and Science University, 3181 S.W. Sam Jackson Park Rd., Portland, OR 97239-3098, USA

e-mail: wolfeb@ohsu.edu recently [4, 5]. The central role of inflammation is reviewed by O'Rourke.

\section{Bariatric surgery results in superior weight loss}

The medical therapy for severe obesity consists of diet and exercise and is enhanced by various forms of instruction, group therapy, individual counselling, and medication. Unfortunately on a population basis, only bariatric surgery results in sustained meaningful weight loss [6]. Three longterm prospective clinical trials have all demonstrated sustained weight loss ranging from $15 \%$ to $30 \%$ or more of total body weight for more than 10 years [6-8]. Associated with this weight loss, multiple studies have demonstrated improved survival in comparison to nonsurgical subjects identified through various databases, as reviewed by Christou [9]. A major component of the explanation for this improved survival is, presumably, a direct result of induction of long-term remission of various life-threatening co-morbidities, including type 2 diabetes, hypertension, obstructive sleep apnea, dyslipidemia, and related cardiovascular risk [10].

\section{Improved safety of bariatric surgery}

The first analysis of an administrative database coupled with a public death index by Flum indicated the mortality rate for bariatric surgery was $1.9 \%$, suggesting that the multiple single-center case series reports had substantially underestimated the incidence of bariatric surgery perioperative mortality [11]. Subsequent examination of a larger database with similar methodology, however, demonstrated a $0.33 \%$ perioperative mortality rate [12]. Most recently, 
low perioperative risk has been reported on the basis of a prospective clinical database as well as analysis of a large administrative database [13, 14].

\section{Goals of the 2009 symposium}

Multiple issues pertinent to bariatric surgery have been addressed by the present symposium. These include examination of specific bariatric surgical procedures and their mechanisms of action. The classical description of mechanisms of action of bariatric surgery has considered procedures as restrictive or malabsorptive or a combination of both. This construct is now known to be a substantial oversimplification of the mechanisms by which the procedures exert their action. Restrictive operations are dependent on induction of learned behavior change. The sensation of fullness, discomfort, or other adverse manifestations of over-eating relative to restrictive capacity are highly variable and ill-defined. Dixon demonstrated further complexity in the mechanisms of action of restrictive procedures when he showed a direct effect of tightening the adjustable gastric band on fasting appetite [15].

Gastric bypass, biliopancreatic diversion (with or without duodenal switch), as well as the abandoned jejunoileal bypass, are procedures thought to include a component of malabsorption. The extent to which malabsorption actually occurs, however, has not been clearly defined, particularly for gastric bypass. In addition, prior studies of energy intake and absorption following intestinal bypass, the prototype malabsorptive procedure, showed that weight loss in fact was predominantly secondary to diminished intake and that malabsorption played a secondary role [16].

Multiple contributions to this symposium examine the role of gut hormones (le Roux), vagal mediation of appetite satiety and gastrointestinal function (Kral), and gut flora (Prachand). Three specific co-morbidities of particular interest in bariatric surgery at the present time are reviewed in detail: diabetes (Dixon), cancer (Adams), and gastroesphageal reflux disease (Patti). It is recognized that many of the other known co-morbidities could well have merited special consideration, but space considerations limited this aspect of the symposium.

As more is learned about the mechanisms of action of the specific bariatric surgical procedures, research to develop medical therapy as well as a focus on specific operations for specific patients will be possible. It remains entirely possible, for example, that lesser operative procedures, such as endoluminal procedures, combined with partial medical therapy will ultimately achieve efficacy. An important research and healthcare policy need is to consider the present low penetration of bariatric surgery in relation to the epidemic of severe obesity. It is not feasible for any healthcare system to perform bariatric surgery for all of the candidates who would potentially benefit. Thus, identification of the best candidates for surgical intervention by determining relative risk for development of endpoints of cardiovascular disease, cancer, and other co-morbid conditions will be of critical importance. Evidence-based guidance for selection of the best candidates for specific operative procedures must remain a long-term goal.

\section{References}

1. World Helath Organization (2000) Obesity: preventing and managing the global epidemic. Report of a WHO consultation (World Health Organ Tech Rep Ser 894; i-xii), 1-253

2. American Society for Metabolic and Bariatric Surgery (2009) Fact sheet: metabolic \& bariatric surgery, 22 Dec 2008

3. Sturm R (2003) Increases in clinically severe obesity in the United States, 1986-2000. Arch Intern Med 163(18):2146-2148

4. Calle EE, Rodriguez C, Walker-Thurmond K et al (2003) Overweight, obesity and mortality from cancer in a prospectively studied cohort of U.S. adults. N Engl J Med 348(17):1625-1638

5. Renehan AG, Tyson M, Egger M et al (2008) Body-mass index and incidence of cancer: a systematic review and meta-analysis of prospective observational studies. Lancet 371(9612):569-578

6. Sjöström L, Narbro K, Sjöström CD et al (2007) Effects of bariatric surgery on mortality in Swedish obese subjects. N Engl J Med 357(8):741-752

7. Christou NV et al. Surgery decreases long-term mortality, morbidity, and health care use in morbidly obese patients. Ann Surg 240:416-424

8. Pories WJ, Swanson MS, MacDonald KG et al (1995) Who would have thought it? An operation proves to be the most effective therapy for adult-onset diabetes mellitus. Ann Surg 222(3):339-350; discussion 350-352

9. Christou NV (2009) Impact of obesity and bariatric surgery on survival. World J Surg. doi:10.1007/s00268-009-0050-2

10. Buchwald H, Avidor Y, Braunwald E et al (2004) Bariatric surgery: a systematic review and meta-analysis. JAMA 292(14): 1724-1737

11. Flum DR, Dellinger EP (2004) Impact of gastric bypass operation on survival: a population-based analysis. J Am Coll Surg 1999(4):543-551

12. Zingmond DS, McGory ML, Ko CY (2005) Hospitalization before and after gastric bypass surgery. JAMA 294(15):19181924

13. The Longitudinal Assessment of Bariatric Surgery (LABS) Consortium (2009) Perioperative safety in the longitudinal assessment of bariatric surgery. N Engl J Med (in press)

14. Encinosa WE, Bernard DM, Du D et al (2009) Recent improvements in bariatric surgery outcomes. Med Care 47(5): $531-535$

15. Dixon AF, Dixon JB, O’Brien PE (2005) Laparoscopic adjustable gastric banding induced prolonged satiety: a randomized blind crossover study. J Clin Endocrinol Metab 90(2):813-819

16. Bray GA, Barry RE, Benfield JR et al (1976) Intestinal bypass surgery for obesity decreases food intake and taste preferences. Am J Clin Nutr 29(7):779-783 